\title{
The economic impact of smoking in Germany
}

\author{
L.K. Ruff*, T. Volmer**, D. Nowak ${ }^{+}$, A. Meyer*
}

The economic impact of smoking in Germany. L.K. Ruff, T. Volmer, D. Nowak, A. Meyer. (C) ERS Journals Ltd 2000.

ABSTRACT: Smoking is a high-risk behaviour affecting health and economic welfare of society. Thus it is important to quantify the economic burden smoking places on social institutions in Germany. Approximately 33.4\% of the male and $20.4 \%$ of the female population are current smokers. This study investigates the health care costs of smoking based on 1996 figures, focusing on the seven most frequent diseases associated with the inhalation of tobacco smoke: chronic obstructive pulmonary disease (COPD, international classification of diseases (ICD) 490-491); lung cancer (ICD 162); stroke (ICD 434-438); coronary artery disease (ICD 410-414); cancer of the mouth and larynx (ICD 140-149, 161) and artherosclerotic occlusive disease (ICD 440).

A data search was carried out on MEDLINE, the German Institute for Medical Documentation and Information, and the Internet as well as in databases of health insurance companies and the German Federal institute of statistics. Direct and indirect costs were calculated separately.

The results estimate the total smoking related health care costs (attributable fraction due to smoking) for COPD to be 5.471 billion EURO (73\%), for lung cancer 2.593 billion EURO (89\%), for cancer of the mouth and larynx 0.996 billion EURO (65\%), for stroke 1.774 billion EURO (28\%), for coronary artery disease 4.963 billion EURO $(35 \%)$ and for artherosclerotic occlusive disease 0.761 billion EURO (28\%). The economic burden of smoking related health care costs for Germany is 16.6 billion EURO. Smoking is therefore responsible for $47 \%$ of the overall costs of these diseases (35.2 billion EURO).

In the view of the high costs for smoking, of which almost $50 \%$ are due to respiratory disease, pneumologists should enhance their effort in primary, secondary and tertiary prevention.

Eur Respir J 2000; 16: 385-390.

Smoking is a high-risk behaviour that affects the health and economic welfare of a society. Health care costs are under pressure in all countries. To rationalize the debate around a ban on tobacco advertizing in the European Parliament [1], it is important to quantify the economic burden smoking places on European health care systems, of particular interest for the authors on that of the Federal Republic of Germany where $\sim 33.4 \%$ of the male and $20.4 \%$ of the female population are current smokers [2]. It is widely acknowledged that cigarette smoking is strongly associated with increased morbidity and mortality due to a number of diseases, the most recognized of which is lung cancer [3]. In addition, the various substances contained in cigarette smoke are partly responsible for malignant tumours of the oral cavity and the pharynx [4] and are a main risk factor for myocardial infarction, cerebral thrombosis, arteriosclerosis and chronic obstructive pulmonary diseases (COPD) such as chronic bronchitis and emphysema [5,6]. Compared to persons who have never smoked, the average decrease in life expectancy has been estimated to be 3-8 yrs depending on the smoking habits [7]. In 1995 the World Health Organization (WHO) estimated that smoking was the cause of about 1.44 million

For editorial comments see page 377.
*Medizinische Klinik, UniversitätsKrankenhaus Eppendorf, Hamburg, **Glaxo Wellcome $\mathrm{GmbH} \& \mathrm{Co}$, Hamburg, ${ }^{+}$Institut und Poliklinik für Arbeits- und Umweltmedizin der Ludwig-Maximilians-Universität München, Ziemssenstr., München, Germany.

Correspondence: A. Meyer

Medizinische Klinik

UniversitätsKrankenhaus Eppdendorf

Martinistr. 52

D-20246 Hamburg

Germany

Fax: 4940428036436

Keywords: Germany

health care costs

smoking

Received: September 161999

Accepted after revision March 82000 male and 0.4 million female deaths in developed countries [8]. Doll and Peto [5] found in their 40 yr follow up of male British doctors, that about half of all regular cigarette smokers will eventually be killed by their habit.

Despite this well documented, hazardous impact on morbidity and life expectancy, the prevalence of smoking in Germany is still enormous. Though consumption is declining in the male population and is stagnating in females [2], it is rising dramatically among young adults [9].

Although the medical evidence is overwhelming, information regarding the economic impact is scarce. Calculations of smoking related economic burden vary widely and are subject to various methodological challenges. The major publication in this area originating from the Office of Technology assessment (OTA) and enforced by the Center of Disease Control (CDC), is based on a spreadsheet model calculation employing a specific methodology termed "Smoking attributable Mortality, Morbidity and Economic Costs" (SAMMEC). Some of the assumptions used in the model regarding the attributable risk fractions will also be utilized in our approach. The OTA estimated the smoking related costs to be US\$68 billion annually (based on 1990 figures), of which, \$21 billion are directly spent for the provision of health care to persons with smoking related illnesses [10]. 
An alternative, but equally comprehensive assessment, the RAND (RAND Corporation, Santa Monica, CA, USA) study on the cost of poor health habits, concluded that life expectancy for a young smoker aged 20 yrs would be reduced by $\sim 4.3$ yrs, or 7 min per cigarette [12]. Furthermore, the study concluded that nonsmokers subsidize the health care insurance of smokers due to lower health care costs, but because nonsmokers live longer, smokers who die at a younger age, subsidize the pension of nonsmokers. Therefore, discounting of future nonhealth cost implications was recommended to adjust for the fact of the medical subsidy. This issue, which is regarded more as an ethical issue than a health economic consideration will be addressed later in the discussion. The transition costs, were not utilized but the foregone opportunity using the human capital approach was calculated. Table 1 summarizes existing literature on the economic burden of smoking-related illnesses.

Current studies undertaken in Canada, the United States and Australia [25], were found to employ at least three different approaches: cost-of-illness [26, 27], demographic [28] and external cost [29, 30]. None of them have been used to provide national estimates for Germany or any other country in Europe. In summary it appeared to us, that although the economic impact of smoking related diseases is discussed widely and controversly, neither German nor European data on the potential financial implications to the German/European health care system and society, exists.

The objective of the present study is to estimate, for the first time, the direct and indirect costs of smoking-related health care costs to the German society.

\section{Material and methods}

The calculation is based on a top-down approach employing nationwide official German statistics and other countrywide databases using 1996 figures from MEDLINE, the Deutsches Institut für Medizinische Dokumentation und Information (German Institute for Medical Documentation and Information) and the Internet as well as databases of health insurance companies and the Ger- man Federal Institute of Statistics. These data are, in many aspects, the most representative source of information available for a top-down cost calculation.

The direct costs of a disease consists of the resources consumed in the health care process, namely the costs of ambulatory care, costs of drug treatment, hospital care, rehabilitation, and long term (nursing) home care. The indirect costs of any given disease are defined as costs incurred by productivity losses, premature retirement and premature mortality. Intangible costs, such as the impact of the condition on the patients' quality of life, have not been assessed, because reliable nationwide data are not available.

Either, the natural units of the resources consumed were identified and multiplied by their respective unit cost or price if costs were unavailable (e.g. hospital charges), or if information on natural units are missing, the costs of the services were directly used in the respective estimation (e.g. drug treatment).

The indirect costs for premature mortality employed a human capital approach. The life years lost up to the age of 65 was therefore multiplied by the gross annual income. All calculations are based on 1996 figures. Table 2 shows the costs and prices used.

In the stepwise approach the overall costs of the diseases known to be associated with smoking were first identified. Although the WHO lists about 25 different diseases, strongly suspected to be causally related to smoking [31], those diseases where sufficient data was available to calculate the burden, employing the ninth revision of the International Classification of Diseases (ICD) [32] were focused upon. The diseases included in the calculation and their respective attributable risks are shown in table 3. Those risks were used to calculate the country-specific smoking-related costs in Germany.

Discounting is used when future costs are assigned to the current year. Indirect costs of premature mortality (i.e. future earnings) and early retirement involve discounting. A discount rate of $4 \%$ was applied (the discount rate is a term used to adjust future costs so that they can be expressed in terms of their present (lower) values; interested

Table 1. - Overview of economic literature on the economic impact of smoking related illnesses and the economic burden of smoking

\begin{tabular}{|c|c|c|c|c|c|c|}
\hline $\begin{array}{l}\text { First author } \\
\text { [Ref.] }\end{array}$ & $\begin{array}{c}\text { Year of } \\
\text { evaluation }\end{array}$ & $\begin{array}{l}\text { Population/ } \\
\text { country }\end{array}$ & $\begin{array}{l}\text { Total number of fatalities } \\
\text { (\% of all death cases) }\end{array}$ & $\begin{array}{l}\text { Total } \\
\text { costs* }\end{array}$ & $\begin{array}{l}\% \text { direct } \\
\text { costs }\end{array}$ & $\begin{array}{l}\text { Cost per } \\
\text { capita }\end{array}$ \\
\hline Сног [12] & 1979 & Ontario, Canada & NA & 2.7 & 18.8 & 246 \\
\hline Сног [12] & 1983 & Ontario, Canada & $(12-17 \%)$ & 3.7 & 37.1 & 331 \\
\hline Collishaw [13] & 1979 & Canada & NA & 9.8 & 21.5 & 331 \\
\hline RICE [14] & 1980 & USA & NA & 70.0 & 37.4 & 264 \\
\hline GORSKY [15] & 1983 & New Hampshire, USA & $(16 \%)$ & 0.3 & 39.1 & 261 \\
\hline SмIтн [16] & 1985 & New York, USA & 27,000 & 5.7 & 39.9 & 314 \\
\hline WASSILAK [17] & 1985 & Georgia, USA & 7,700 & 2.6 & NA & 308 \\
\hline Cummings [18] & 1988 & New York, USA & $30,359(17.7 \%)$ & 4.3 & 34.0 & 238 \\
\hline Kendall [19] & 1989 & Toronto, Canada & NA & 1.2 & 11.7 & 275 \\
\hline DAVIS [20] & 1989 & Missouri, USA & NA & 1.3 & 31.9 & 240 \\
\hline ADAMS [21] & 1989 & Connecticut, USA & $(19.3 \%)$ & 1.0 & 28.7 & 298 \\
\hline РінA (OTA) [22] & 1990 & USA & 416,829 & 50.7 & 30.6 & 215 \\
\hline WiLLIAMS [23] & 1990 & Texas, USA & 24,600 & 4.5 & 29.4 & 239 \\
\hline CHUDY [24] & 1992 & Wisconsin, USA & NA & 1.0 & 31.0 & 189 \\
\hline Collins $^{+}$ & 1992 & Australia & NA & 3.8 & 28.9 & 206 \\
\hline
\end{tabular}

All monetary figures are reported in 1996 US Dollars, $4 \%$ discount rate. ${ }^{*}$ : billion dollars; ${ }^{+}$: unpublished data (D.J. Collins and H.M. Lapsley). NA: data not available. [10, 25]. 
Table 2. - Country-specific item costs in Germany*

Costs used in the calculation

\begin{tabular}{lc}
\hline Average gross income per worker per year & 31633.63 \\
Average hospital rate per day & 277.63 \\
Average rehabilitation rate per day & 119.25 \\
Average cost of doctors' services (per case) & 41.31 \\
Discount rate & $4 \%$ \\
\hline
\end{tabular}

*: costs shown in EURO.

readers can obtain a more detailed description of the calculation methods and numbers upon request).

\section{Results}

The total health care costs of tobacco use in 1996 in Germany are 16.6 billion EURO (table 4). Direct costs account for $51 \%$ of the total; indirect costs account for $49 \%$. In chronic diseases, like COPD, cardiovascular disease and stroke, the direct costs make up $63 \%$ of the total. In the case of diseases with high premature mortality, such as cancer of the oral cavity, pharynx, larynx and lung - smoking causes far higher indirect costs. The distribution in the latter case is $20.4 \%$ direct costs versus $79.6 \%$ indirect costs. Treatment in acute hospitals accounts for $27 \%$ of direct costs. Working days losses, premature retirement and premature death are broadly equal factors, making up $28 \%, 33 \%$ and $39 \%$ respectively of the indirect costs (table 4).

The biggest economic impact is the cost associated with treating smoking related COPD, followed by treating consequences of smoking related coronary heart diseases, lung cancer, stroke and other cerebrovascular diseases, arterial occlusive disease and cancer of the larynx, pharynx and oral cavity. COPD alone accounts for 5.471 billion EURO, roughly one third of the overall estimated costs attributable to smoking (fig. 1).

The respiratory diseases, COPD and lung cancer, caused $49 \%$ of the allocated smoking-related healthcare costs (fig. 2).

The calculated per capita costs are 205.96 EURO. The result is comparable to figures from the literature for other countries (compare table 1) [25]. In 1996 about 137,000 people died due to a smoking-related disease. This is equivalent to $15.6 \%$ of all deaths. The net reduction in life span attributable to smoking is $1,604,396$ years.

Table 3. - Diseases included in the calculation

\begin{tabular}{lcc}
\hline Disease category & $\begin{array}{c}\text { ICD-9 } \\
\text { code }\end{array}$ & $\begin{array}{c}\text { Attributable } \\
\text { risk \% }\end{array}$ \\
\hline Oral cavity and pharynx cancer & $140-149$ & 65 \\
Larynx cancer & 161 & 65 \\
Lung cancer & 162 & 89 \\
CHD & $410-414$ & 35 \\
Stroke, CVD & $433-438$ & 28 \\
AOD & 440 & 28 \\
COPD & $490-491$ & 73 \\
\hline
\end{tabular}

CHD: coronary heart disease; CVD: cerebovascular disease AOD: atherosclerotic occulsive disease; COPD: chronic obstructive pulmonary disease.
Table 4. - Smoking-attributable health care costs of smoking-related diseases

\begin{tabular}{lcrrr}
\hline & & \multicolumn{2}{c}{ Costs } & \\
\cline { 3 - 4 } Disease category & $\begin{array}{c}\text { ICD-9 } \\
\text { code }\end{array}$ & Direct & Total & $\begin{array}{c}\text { Direct costs } \\
\text { as \% of total }\end{array}$ \\
\hline $\begin{array}{l}\text { Oral cavity and } \\
\text { pharynx cancer }\end{array}$ & $140-149$ & 124 & 771 & 16.0 \\
$\begin{array}{l}\text { Larynx cancer } \\
\text { Lung cancer }\end{array}$ & 161 & 47 & 226 & 20.7 \\
CHD & 162 & 559 & 2593 & 21.6 \\
Stroke CVD & $410-414$ & 2692 & 4963 & 54.2 \\
AOD & 4438 & 1162 & 1774 & 65.5 \\
COPD & $490-491$ & 3269 & 5471 & 82.0 \\
Total & & 8478 & 16561 & 51.1 \\
\hline
\end{tabular}

Data represents costs in million EURO. CHD: coronary heart disease; CVD: cerebovascular disease; AOD: atherosclerotic occlusive disease; COPD: chronic obstructive pulmonary disease.

\section{Discussion}

This is the first calculation of the direct and indirect costs of smoking related health care costs in Germany. The stepwise burden-of-illness approach turned out to be a suitable instrument for quantifying health care costs. With total smoking related health care costs of 16.6 million EURO in the year 1996 and estimated per capita costs of 238 US\$ (205.96 EURO), the results of this analysis for Germany are widely comparable to the findings of various other international authors for the other developed countries. However, quantifying the cost of smoking is a difficult task because tobacco use is infiltrating many aspects of life and the methods of calculation of the health care costs are not indisputable.

On one hand the figure is very likely to be conservative, because some of the diseases which are known to be related to smoking, as discussed by the WHO, were not included (e.g. cancers of pancreas, oesophagus, kidney and other urinary organs). They were excluded from this calculation due to the lack of appropriate information either on the attributable risks or on respective economic aspects.

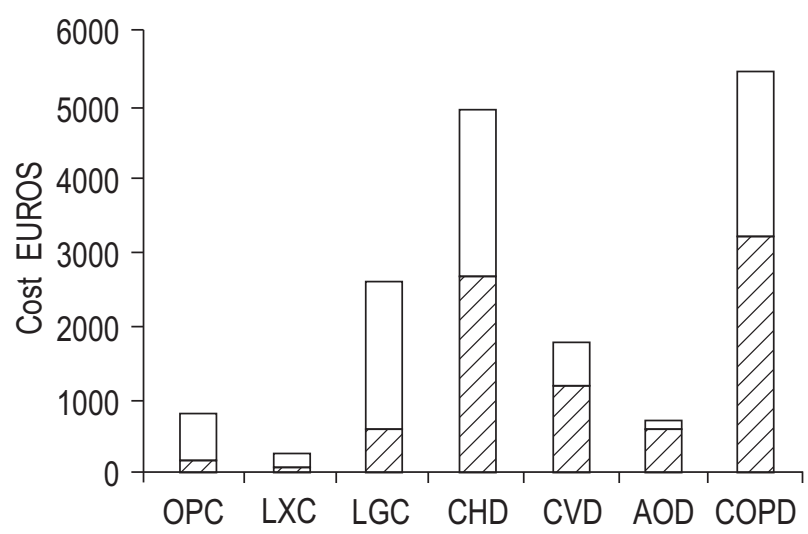

Fig. 1. - Total costs made up of direct costs $(\mathbb{Z})$ and indirect costs $(\square)$ in million EURO by disease category. OPC: oral cavity and pharynx cancer; LXC: larynx cancer; LGC: lung cancer; CHD: coronary heart disease; CVD: cerebovascular disease; AOD: atherosclerotic occlusive disease; COPD: chronic obstructive pulmonary disease. 


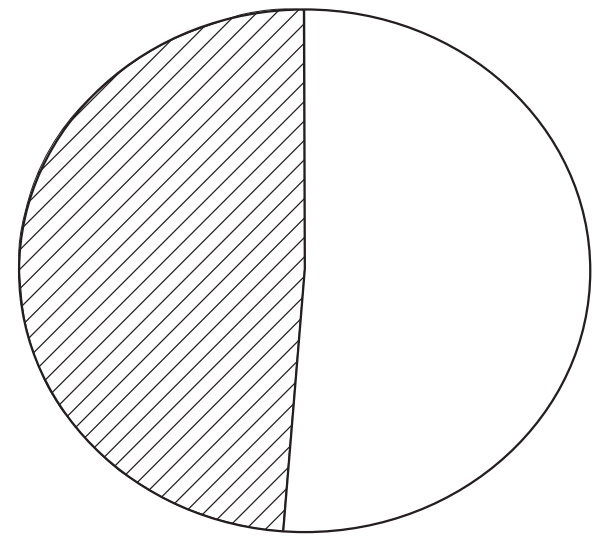

Fig. 2. - Relative importance of lung diseases as a proportion of total smoking related economic burden. $\mathbb{Z}$ : chronic obstructive pulmonary disease, lung cancer; $\square$ : coronary heart disease, cerebovascular disease, atherosclerotic occlusive disease, larynx cancer, oral cavity and pharynx cancer.

Furthermore other health consequences indirectly related to tobacco consumption, such as medical care costs attributable to burning wounds or fire and diseases attributed to passive smoking, had to be omitted due to lack of reliable quantitative data. Even the well recognized and important aspect of parental smoking and its health impact on the children like increased risk of respiratory distress [34], sudden infant death syndrome [35], low birthweight, pregnancy complication and subsequent development abnormalities [36] were not included due to missing data for Germany.

The attributable risks of mortality and morbidity were taken from international available literature sources. It is true, that the attributable risks were taken from hard patient endpoint data (mortality) and extrapolated to morbidity. This is recognized as a valid procedure for lung cancer, larynx cancer, oral cavity and pharynx cancer. Given the recent discussion on COPD [5] and atherosclerotic occlusive disease (AOD) [37] it also seems appropriate in these disease areas. It is not yet established, and more disputable, in the area of multi-factorial diseases such as coronary heart disease (CHD) and cerebovascular disease (CVD) (stroke). However, it is more likely that this procedure will lead to an underestimation of the risk and impact of COPD and AOD because of the potential misclassification on death certificates.

On the other hand it can be assumed that smoking represents solely an additional risk, without any reduction in future health care costs attributable to the progression of other chronic conditions like Parkinson, Alzheimer's disease or ulcerative colitis [38]. Taken as a whole, the benefits due to any potential protective effects of smoking are quantitatively much smaller and considerably less serious than those caused by smoking [39]. In addition, we have to take into consideration that premature mortality due to smoking-related disease excludes resource consumption due to other age-typical smoking-related diseases (Panel on Cost-Effectiveness in Health and Medicine categories 1 and 2 [40]). Also, as discussed in the RAND study, the disease-associated risks are difficult to adjust for the overlap or duplicacy of the individual behaviour-linked conditions within the same population, considering the fact that unhealthy (and healthy) lifestyles behaviours tend to cluster.

One further area of discussion is buried in the fact that we did not correct the calculation for the costs of additional life years for the surviving nonsmokers (Panel on CostEffectiveness in Health and Medicine category 3). The panel [40] suggests the inclusion of all health related cost aspects, but does not specify a distinct method for it, whereas the German guidelines for health economic studies [41] do not require such a calculation at all. The effect could be an overestimation of health care costs, if we assume, that those people die early from smoking related disease, and can therefore not suffer from other nonsmoking-related diseases at later life stages. However, several studies found that, the majority of health care costs occur in the last years of life regardless of the age [42].

A general problem is arising from the given data sources. Health services' statistics reflect expenditure, rather than actual costs. In the case of direct costs, the use expenditure figures in lieu of costs was accepted. In the case of indirect costs, in accordance with the human-capital method [42], income figures was used as structural data in order to evaluate the opportunity costs attributable to illness. An example is the costs due to early retirement, where the average income per capita was applied to the years of employment lost rather than the average pension per capita. The calculation of indirect costs based on the human capital approach tends to favour, in accordance with the majority of the population, interventions for younger age groups. It might therefore lead to potential overestimation in diseases with high mortality in early life stages (e.g. cancer). Almost two third of the costs are caused by chronic diseases, which make any potential bias towards overestimation somewhat minuscule in effect.

This calculation employed a top-down approach to calculate the burden-of-illness. The advantage of this method is that selection bias, which frequently occur in mostly nonrepresentative bottom-up calculations, is eliminated. On the other hand, using official statistics and employing average resource consumption patterns might foster a regression to the mean, thereby at best underestimating the true burden.

Any possible impact on the pension system was not expanded for several reasons. Firstly, that continuous smoking is not only a voluntary consumer decision, but driven by the addictive element of nicotine dependence. Therefore, it is morally doubtful and almost cynical to us to compare potential savings from foregone pension payments with the health care expenditure. Secondly, the role of health care provision is to ensure a longer and healthier life. The authors are unaware of any calculation, where the cost of oncology care is compared with the pension consequences. And thirdly, potential benefits from prevention measures for the public health are so dominating that, if smoking prevention proved to be $100 \%$ successful, the actions to be taken to adjust the financing of pension system would then be outweighed by the positive health effects.

One further area of bias is the use of WHO-estimates on the attributable risk [33] for our calculation. Smokingattributable fractions (SAF) are the proportion of cases of diseases or deaths that can be regarded as causally linked 
to cigarette smoking. For each of the smoking-related diagnoses, the SAF represents the proportion by which the mortality would be reduced if exposure to cigarette smoke were eliminated. To calculate SAF values, diagnosis- and sex-specific relative risk estimates for smoking-related diseases and data on smoking prevalence must be available [43]. Reported relative risks associated with smoking differ greatly between studies. These differences may reflect true biological differences between populations, or may be research effects introduced by differences in design (factors such as amount smoked or smoking duration [44]). The used WHO-estimate is based on studies in population with different socioeconomic and cultural backgrounds. In the absence of German data, the attributable risks for the aforementioned diseases are assumed to be valid estimates for Germany. This assumption however needs to be proven in further observational studies.

Using smoking attributable risk fraction for the calculations, we assume the SAF to be an indicator of true health service demand for those diseases. This assumption could be challenged, because the hazardous effects of cigarette smoke might be counterbalanced by a different health care consumption pattern of smoking individuals. Also the authors proceed from the idea that all smoking attributable fractions are exclusively attributable to their behaviour, ignoring potential and known confounders such as low income and low socioeconomic status. Finally, allowances were not made for the confounding factor that smokers and nonsmokers might have different risk and health behaviour besides their smoking status due to different personality, as reported [45].

Last but not least, the issue of whether "cost of illness" studies misguide decisions [46] should be addressed. Scarce resources might most efficiently be employed to study interventions. This has been performed for smoking cessation programmes in a wide variety of studies [47, 48]. Nonetheless this analysis was performed to highlight the economic consequences of smoking, which justify more efforts not only to support smokers in their efforts to stop smoking, but also to keep young adolescents away from cigarettes or to turn starting smokers into nonsmokers again. In this respect, this burden of smoking paper hopefully guides health policy attention and decision making.

\section{Conclusion}

Smoking-related diseases represent independent of methodological uncertainties an enormous economic burden on the health care system. Although the quantification of the health care costs of smoking is difficult, more measures are needed to intensify primary, secondary and tertiary prevention. Due to the high proportion of respiratory conditions from the total burden, pneumologists are challenged to increase their efforts to reduce this menace.

The authors' estimation of total health care costs can therefore only be a first step in assessing the overall impact of smoking on health care costs in Germany. The results indicate that a comparable burden was identified in other Western societies. Further studies on the economic impact of smoking cessation will be needed to prove and justify the prevention efforts.
Acknowledgement. The authors would like to thank GlaxoWellcome for funding a travel grant to allow presentation of this work as an abstract at the American Thoracic Society meeting in San Diego 1999.

\section{References}

1. Watson R. EU will ban tobacco adverts from 2001. BMJ 1998; 316: 1333.

2. Statistisches Bundesamt. Daten des Gesundheitswesens. Ausgabe 1997. Band 91: Schriftenreihe des Bundesministeriums für Gesundheit. Baden-Baden, Nomos-Verlag, 1997; pp. 122-123.

3. Doll R, Hill AB. Study of the aetiology of carcinoma of the lung. $B M J 1952$; ii: $1271-1286$.

4. US Department of Health and Human Services. The Health Consequences of Smoking: Cancer. A Report of the Surgeon General. DHSS Publication PHS 82-50179. Washington, US Department of Health and Human Services, 1982.

5. Doll R, Peto R. Mortality in relation to smoking: 40 year's observation on male British doctors. BMJ 1994; 309: 901-911.

6. McBride PE. The health consequences of smoking. Cardiovascular diseases. Med Clin North Am 1992; 76: $333-$ 353.

7. West RR. Smoking: its influence on survival and causes of death. JR Coll Physicians Lond 1992; 26: 357-366.

8. World Health Organization. Tobacco or health: a global status report. Geneva, World Health Organization, 1997.

9. Junge B. Tabak-Zahlen und Fakten zum Konsum. In: Jahrbuch Sucht '99. Geesthacht: Neuland-Verlag, 1999; $20-45$

10. Piha T, Besselink E, Lopez AD. Tobacco and health. World Health Stat Q 1993; 46: 188-194.

11. Rice DP, Kelman S, Miller LS. Estimates of economic costs of alcohol and drug abuse and mental illness, 1985 and 1988. Public Health Rep 1991; 106: 280-292.

12. Choi BC, Nethercott JR. The economic impact of smoking in Canada. Int J Health Plann Manage 1988; 3: 197-205.

13. Collishaw NE, Myers G. Dollar estimates of the consequences of tobacco use in Canada 1979. Can J Public Health 1984; 75: 192-199.

14. Rice DP, Hodgson TA, Sinsheimer P, Browner W, Kopstein AN. The economic costs of the health effects of smoking, 1984. Milbank $Q$ 1986; 64: 489-547.

15. Gorsky RD, Schwartz E, Dennis D. The morbidity, mortality, and ecomomic costs of cigarette smoking in New Hampshire. J Community Health 1990; 15: 175-183.

16. Smith PF, Shultz JM, Morse DL. Assessing the damage from cigarette smoking in New York State. N Y State $J$ Med 1990; 90: 56-60.

17. Wassilak SG, Smith JD, McKinley TW, Sikes RK. The health and economic burden of cigarette smoking in Georgia in 1985. J Med Assoc Ga 1989; 78: 601-605.

18. Cummings KM, Stiles J, Mahoney MC, Sciandra R. Health and economic impact of cigarette smoking in New York State, 1987-1989. N Y State J Med 1992; 92: 469-473.

19. Kendall PRW. The health and economic impacts of smoking in the city of Toronto. Technical Report. Toronto, Department of Public Health, 1992.

20. Davis JR, Eischen M, Brownson RC. The health and economic costs of smoking in Missouri. Mol Med 1990; 87: 877-880.

21. Adams ML. The public health impact and economic cost 
of smoking in Connecticut-1989. Conn Med 1994; 58: 195-198.

22. Piha T, Basselink E, Lopez AD. Tobacco or health. World Health Stat Q 1993; 46: 188-194.

23. Williams AF, Franklin J. Annual economic costs attributable to cigarette smoking in Texas. Tex Med 1993; 89: $56-60$.

24. Chudy N, Remington PL, Yoast R. The increasing health and economic burden from cigarette smoking in Wisconsin. Wis Med J 1992; 91: 633-636.

25. Robson L, Single E. Literature review of studies on the economic costs of substance abuse: a report of the Canadian Centre on Substance Abuse 1995. Ottawa, 1995.

26. Rice DP. Estimating the Cost of Illness. Health Economics Series, no. 6. Rockville, MD: Department of Health, Education and Welfare. DHEW Publication No. (PHS) 947-6.

27. Rice DP, Hodson TA, Kopstein AN. The economic cost of illness: a replication and update. Health Care Fin Rev 1985; 7: 61-80.

28. Manning WG, Keeler EB, Newhouse JP, Sloss EM, Wasserman J. The costs of poor health habits. A RAND Study. Cambridge, Harvard University, 1991.

29. Forbes WF, Thompson ME. Estimating the health care costs of smokers. Can J Public Health 1983; 74: 183-190.

30. Collins DJ, Lapsley HM. Estimating the economic costs of drug abuse in Australia. Canberre, Australian Publishing Service, 1991.

31. Meltzer EO. Prevalence, economic and medical impact of tobacco smoking. In: Annuals of Allergy 1994; 73: 381388.

32. Bundesministerium für Jugend, Familie, Frauen und Gesundheit. Internationale Klassifikation der Krankheiten. Verletzungen und Todesursachen (ICD) 1979. 9. Revision, 2nd Edn. Cologne, Kohlhammer Verlag, 1988.

33. World Health Organization. Estimates based on: Peto R, Lopez AD, Boreham J, Thun M, Heath C. Mortality from smoking in developed countries. Oxford, Oxford University Press, 1994

34. Cook DG, Strachan DP. Summary of effects of parenteral smoking on the respiratory health of children and implications for research. Thorax 1999; 54: 357-366.

35. Mitchell EA, Ford RP, Stewart AW, et al. Smoking and the sudden infant death syndrome. Pediatrics 1993; 91: 893-896.
36. Hay J. The harm they do to others: aprimer on the external costs of drug abuse. In: Lazear E, Krauss M, eds. Searching for Alternatives: Drug Control Policy in the United States. Stanford, Hoover Institution Press, 1991; pp. 200-225.

37. Howard G, Wagenknecht LE, Burke GL, et al. Cigarette smoking and progression of atherosclerosis: The Atherosclerosis Risk in Communities (ARIC) Study. JAMA 1998; 14: 279: 119-124.

38. Wald NJ, Hackshaw AK. Cigarette smoking: an epidemiological overview. Br Med Bull 1996; 52: 1-11.

39. Bolliger CT. Progress in Respiratory Research - The Tobacco Epidemic. Basle, Karger, 1997, 97.

40. Gold MR, Siegel JE, Russel LB, Weinstein MC, eds. Cost-Effectiveness in Health and Medicine. New York, Oxford University Press, 1996.

41. Hanoveraner Consensus-Group. German Recommendations for health economic evaluations - revised version of the Hanover Consensus. (Deutsche Empfehlungen zur gesundheitsökonomischen Evaluation - Revidierte Fassung des Hanoveraner Konsens). Gesundh Ökon Qual Manag 1999; 4: A62-A65.

42. Leidl R. Der Effizienz auf der Spur: Eine Einführung in die ökonomische Evaluation. In: Schwartz FW, Badura B, Leidl R, Raspe H, Siegrist J, eds. Das Public Health Buch. Munchen, Urban \& Schwarzenberg-Verlag, 1998; p. 356.

43. Shultz J, Novotny T, Rice D. Quantifying the Disease Impact of Cigarette Smoking with SAMMEC II Software. Seventh World Conference of Tobacco and Health. Perth, Western Australia, 1990.

44. Van de Mheen PJ, Gunning-Schepers LJ. Differences between studies in reported relative risks associated with smoking: an overview. Public Health Rep 1996; 111: 420-427.

45. Leu RE, Schaub T. Economic aspects of smoking. Effective Health Care 1984; 3: 111-123.

46. Drummond MF, Stoddart GL, Torrance GW. Methods for the economic evaluation of health care programmes. Oxford, Oxford University Press, 1990.

47. Tonnesen P. Smoking cessation programs. In: Hansen HH, ed. Lung Cancer. Amsterdam, Kluwer, 1994.

48. Silagy C, Mant D, Fowler G, et al. Meta-analysis on efficacy of nicotine replacement therapies in smoking cessation. Lancet 1994; 343: 139-142. 